\title{
Barrett's esophagus and adenocarcinoma
}

\author{
Z.W. LI. MD, R. WENSEL, MD, FRCP, A.B.R. THOMSON. MD, PHD, FRCPC, FACP
}

ABSTRACT: As association between Barrett's esophagus and adenocarcinoma of the esophagut is relatively frequent. Survival with adenocarcinoma is generally poor. Routine surveillance endoscopy is suggested with generous biopsy material and brush cytology to detect either high grade dysplasia or intramucosal carcinoma in patients with Barrett's esophagus. Individual cases of high grade dysplasia should be independently confirmed by another pathologist familiar with dysplasia grading. Esophagectomy should be recommended for those patients with high grade dysplasia whose risk for surgery is outweighed by the possible presence or development of cancer. Can J Gastroenterol 1988;2(2):75-78

Key Words: Adenocarcinoma, Esophagitis, Gastroesophageal reflux disease

B ARRETT'S ESOPHAGUS IS A CONdition in which normal esophageal stratified squamous mucosa is replaced by columnar mucosa. Much has been learned about Barrett's esophagus since its initial description in 1950 (1). It develops in about $10 \%$ of patients with chronic gastroesophageal reflux (2-5). Barrett's esophagus is a condition of clinical concern because of an increased risk of adenocarcinoma as first described by Allison and Johnstone in 1953 (6). Since then there have been numerous reports relating to an adenocarcinoma occurring in as many as $10 \%$ of patients with Barrett's esophagus (7-11).

The risk of esophageal adenocarcinoma in patients with Barrett's esophagus appears to be about 30 to 40 times that in the general population (12). In the

Nutrition and Metabolism Research Group, Division of Gastroenterology, Department of Medicine, University of Alberta, Edmonton, Alberta

Correspondence and reprints: Dr A.B.R. Thomson, 519 Robert Newton Research Building, University of Alberta, Edmonton, Alberta T6G 2C2. Telephone (403) 432-6490

Dr Li Zhang-Wan, is an associate professor and associate chief physician of internal medicine,

First Hospital Harbin Medical University, Heilongjiang, PRC

Received for publication February 1988. Accepted April 1988

past, glandular tumours involving the esophagogastric junction were often dismissed uncritically as cancers of the gastric cardia that invaded the esophagus. However, strong circumstantial evidence now suggests that many adenocarcinomas of the esophagogastric junction actually arise in Barrett's mucosa. Adenocarcinoma with Barrett's esophagus accounts for about 5 to $10 \%$ of all esophageal cancers, (the majority being squamous cell carcinoma).

Adenocarcinoma of the esophagus has a poor prognosis. Sanfey et al (13) reported on 32 patients with adenocarcinoma arising in a Barrett's esophagus of whom 21 underwent esophagogastrectomy with a survival rate of $34 \%$ at two years and $15 \%$ at five years. Skinner and associates (14) report a $22 \%$ survival rate for five years, and a median survival of 23 months (15). Because of the relatively high frequency of adenocarcinoma, poor patient survival, the lateness of clinical symptoms and the relative diagnostic insensitivity of radiologic examinations, surveillance by sequential endoscopic examinations is currently recommended for patients with Barrett's esophagus $(4,5,16,17)$. 
Barrett's mucosal change is thought to be secondary to chronic gastroesophageal reflux. Acid insult to the lower esophagus results in ulceration with reepithelialization taking place from the gastric side. In such patients the distal portion of the esophagus becomes lined with columnar mucosa, with a potential to undergo dysplasia and malignant degeneration.

Cigarette smoking and alcohol ingestion may act as co-carcinogens in adenocarcinoma of the esophagus. Sanfey et al (13) reported that life histories regarding cigarette smoking were available for 23 of 32 patients with adenocarcinoma arising in Barrett's esophagus. Only two of the 23 patients had never smoked. Other authors have reported an association between Barrett's adenocarcinoma, cigarette smoking and regular alcohol intake $(14,18)$. Thus, cigarette smoking and alcohol ingestion may be important factors in cancer developing in Barrett's esophagus, as is also the case with squamous carcinoma.

\section{CLINICAL FEATURES}

Adenocarcinoma in association with Barrett's esophagus is most common in males in the fifth and sixth decade of life who often smoke, drink and have a past history of esophagitis, hiatal hernia or stricture. Patients with reflux esophagitis secondary to scleroderma, and those with reflux caused by a cardiomyotomy for achalasia, are also at risk of developing cancer,

In a review of 121 patients with adenocarcinoma arising in a Barrett's esophagus as reported by Siogren and colleagues (5), the mean age at diagnosis was 57 years range 23 to 88 years. The male to female ratio was 5.5:1, an exaggerated male predominance over that of Barrett's esophagus in general. Dysphagia was the predominant presenting symptom in $87 \%$, a hiatal hernia was often present in $71 \%$, and $64 \%$ of patients had symptoms of reflux esophagitis for one to 40 years.

The site of adenocarcinoma in relation to the gastroesophageal junction and the squamocolumnar junction is variable, although the incidence appears highest in the distal one-third of the esophagus.

\section{DIAGNOSIS}

Surveillance by serial endoscopic examinations with esophageal biopsies: Barrett' $\mathrm{s}$ mucosa is classified as: distinctive specialized type, cardiac type, fundic type or dysplastic. Dysplasia is classified as intermediate grade or high grade, and is based on the classification used for gastric dysplasia.

Specialized columnar epithelium is the most common of the three types of mucosa in adults with Barrett's esophagus. In a study of both endoscopic biopsy specimens and esophagectomy specimens, Hamilton and colleagues (19) assessed the relationship between dysplasia in Barrett's esophagus and invasive adenocarcinoma. Of 14 patients with Barrett's esophagus and endoscopic biopsy specimens indicating dysplasia, six patients had high grade $(43 \%)$, three had intermediate grade $(21 \%)$ and five had low grade $(36 \%)$ dysplasia. Distinctive type columnar epithelium was both the most common type of epithelium noted in the group (13 of 14) and the most common type associated with high grade dysplasia (six of six). Of the six patients with high grade dysplasia, five underwent esophagectomy and three of these were found to have superficially invasive adenocarcinoma. In one patient tumour extended only to the muscularis mucosa and in two patients tumour reached the submucosa. The other patient with high grade dysplasia and the eight patients with intermediate or low grade dysplasia were not yet known to have developed carcinoma on follow-up.

In a study of the resected specimens (19), high grade dysplasia was strongly associated with adjoining invasive adenocarcinoma; $84 \%$ of areas with invasion had high grade dysplasia and $92 \%$ of areas with high grade dysplasia showed invasion. Intermediate grade dysplasia was found in six of the areas and low grade in one of the areas adjacent to microscopically invasive carcinoma. In areas of Barrett's esophagus that did not adjoin invasive carcinoma in the resected specimens, high grade dysplasia was noted infrequently.

Lee (20) has also confirmed previous observations suggesting that high grade dysplasia is closely linked to the presence of adenocarcinoma. He performed a careful retrospective analysis of a large number of resected specimens from patients with Barrett's esophagus who developed adenocarcinoma. The presence of high grade dysplasia was both a sensitive and specific marker for the presence of adjacent invasive carcinoma. The strong association between high grade dysplasia and adenocarcinoma in resected specimens would appear to argue for patients with high grade dysplasia being considered for elective esophagectomy.

In as much as the prognosis of invasive adenocarcinoma arising in Barrett's esophagus is so poor, identification of a high risk group or earlier identification of the lesion itself might improve survival. By regular endoscopy with adequate biopsy it may be possible to detect early intramucosal carcinomas in certain patients. It is felt that endoscopic biopsy specimens should be taken with a jumbo biopsy forceps $2 \mathrm{~cm}$ apart throughout the entire Barrett's area. If dysplasia is identified annual examinations are recommended. If high grade dysplasia develops esophagectomy should be considered.

Esophageal cytologic examination: Brush cytology is an excellent addition to endoscopic biopsies and may provide independent confirmation of the presence of cancer (21).

Radiologic examination: The barium swallow has a diagnostic sensitivity for Barrett's esophagus of only $24 \%$ (22). A reticular pattern of the esophageal mucosa may be observed with use of double contrast esophagography, but this finding is neither sensitive nor specific for Barrett's esophagus. It more probably reflects difficulty in prospectively diagnosing a mucosal lesion that usually has only nonspecific radiographic findings. The combination of hiatal hernia, esophageal ulcer and mid-esophageal stricture is highly suggestive of Barrett's esophagus. Unfortunately, in retrospective series, no more than 25 to $30 \%$ of patients with Barrett's esophagus have been found to have this triad $(23,24)$. Thus, radiological examination of the esophagus is not recommended for detecting or following Barrett's esophagus. Flow cytometry: Reid et al (25) used flow cytometry and histology to evaluate 317 biopsy specimens from 64 con- 
secutive patients who were in a cancer surveillance program for Barrett's esophagus, plus three additional patients with adenocarcinoma in Barrett's esophagus. All patients with dysplasia or adenocarcinoma had evidence of genomic instability (aneuploidy) or abnormalities of mucosal proliferation as detected by flow cytometry. In a small subset of patients with specialized metaplastic epithelium whose specimens were histologically negative or indefinite for dysplasia, the mucosa had aneuploid cell populations or proliferative abnormalities that were otherwise found only in dysplasia or carcinoma. Fur ther study may prove that this subset of patients merits more frequent endoscopic biopsy surveillance because of an increased risk for developing carcinoma.

Thus, flow cy tometry is capable of detecting alterations in DNA content or proliferation or both, that are present in high frequency in Barrett's dysplasia and carcinoma. Because the abnormalities detected by flow cytometry correlate well with the conventional histologic diagnosis of dysplasia and carcinoma, they may prove to be a valuable objective adjunct in the diagnosis of dysplasia and carcinoma in Barrett's esophagus.

Acid sulphated mucins: Other markers have recently been proposed to detect early cancer of the esophagus including changes in mucin staining to detect acid sulphated mucins. Unfortunately, recent studies have shown that acid sulphated mucins are present too frequently in Barrett's epithelium without dysplasia to be of use in defining a subgroup at increased risk of dysplasia.

\section{STAGING SYSTEM}

Rosenberg and co-workers (18) reported an analysis of adenocarcinoma in Barrett's esophagus, utilizing a staging system. They under took a study of the progression of changes that take place in patients with adenocarcinoma arising in a Barrett's esophagus and developed a staging system based on the extent of the malignancy (as determined by surgery and by pathologic examination of the tumour). This staging system is as follows: (I) Carcinoma limited to the mucosa (including carcinoma in situ) not extending beyond the muscularis mucosa with negative nodes; (II) carcinoma limited to the esophageal wall but not extending to the adventitia, with negative nodes; (III) any of the above with involved regional lymph nodes or full thickness wall penetration of the tumour to the adventitia, without invasion of adjacent organs; and (IV) carcinoma invading adjacent organs or with distant metastases.

The finding of a progression of changes from dysplasia to in situ neoplasia to invasive malignancy suggests metaplasia as the first step in this process. Multiple foci of malignant change in Barrett's esophagus have been frequently reported.

\section{MANAGEMENT}

Medical treatment: Patients who have symptomatic or objective evidence of reflux esophagitis should receive vigorous standard medical treatment including $\mathrm{H} 2$ antagonists, prokinetic agents and dietary restrictions. Kothari and associates (27) reported that ulcers in five patients with Barrett's, refractory to antacids, healed in eight to 16 weeks with cimetidine $1.26 \mathrm{~mL} /$ day. It is not known if the risk of dysplasia or carcinoma is reduced by such medical therapy.

Surgical treatment. Antireflux surgery: Some investigators have claimed at least partial regression of Barrett's epithelium after successful antireflux procedures $(3,10)$. Several authors advocate an antireflux procedure for most patients with Barrett's esophagus, but it is not known whether the occurrence of adenocarcinoma can be prevented.

Esophagectomy: A difficult problem facing doctors who deal with patients

acquired? An experimental study of esophageal mucosal regeneration in the dog. Surgery 1970;68:175-82.

3. Goldman MC, Beckman RC. Barrett's syndrome: Case report with discussion about concepts of pathogenesis. having Barrett's esophagus is the timing of a surgical resection before invasive adenocarcinoma develops. Endoscopic surveillance biopsies are reassuring if they are negative for dysplasia. However, if dysplasia is found on light microscopy, it may be difficult to determine whether the morbidity of a surgical resection is offset by a sufficiently high chance for discovering concomitant early invasive adenocarcinoma.

Several workers (17-19) suggest that the dysplasia-carcinoma sequence most commonly occurs in Barrett's mucosa of the distinctive type. High grade dysplasia in Barrett's mucosa is a marker indicating high probability of invasive carcinoma and, therefore, the presence of high grade dysplasia in biopsy specimens of Barrett's mucosa is probably an indication for total esophagectomy in suitable surgical candidates. A more extensive esophagectomy is required than can be performed using the Lewis approach or a left thoracotomy. Rosenberg and others (18) currently favour a procedure that places the esophagogastric anastomosis in the neck. When either the stomach or the colon is used as an esophageal replacement, it is brought up to the neck through a substernal tunnel. This operative approach is best for all patients with esophageal cancer, irrespective of the cell type.

Patients found to have low grade dysplasia should receive intensive medical treatment for reflux esophagitis for up to 12 weeks, at which time esophagoscopy should be repeated to obtain multiple esophageal biopsy specimens. $\mathrm{Pa}$ tients whose biopsy specimens show histologic improvement will require intense surveillance (eg, an examination every three to six months) until at least two consecutive endoscopic examinations reveal no dysplastic epithelium. Continued intensive treatment and surveillance are recommended in patients whose repeat biopsies reveal persistent low grade dysplasia.

Gastroenterology 1960;39:104-10.

4. Bozymski EM, Herlihy K, Orlando RC. Barrett's esophagus. Ann Intern Med 1982;97:103-7.

5. Siogren RW, Johnson LF. Barrett's esophagus: A review. Am J Med 
1983;74:313-20.

6. Allison PR, Johnstone AS. The oesophagus lined with gastric mucous membrane. Thorax 1953;8:87-101.

7. Spechler SJ, Robbins AH, Rubins HB, et al. Adenocarcinoma and Barrett's esophagus: An overrated risk? Gastroenterology 1984;87:927-33.

8. Cameron AJ, Ott BJ, Payne WS. Incidence of adenocarcinoma in columnar-lined (Barrett's) esophagus. N Engl J Med 1985;313:857.

9. Messian RA, Hermos JA, Robbins AH, et al. Barrett's esophagus: Clinical review of 26 cases. Am J Gastroenterol 1978;69:458-66.

10. Sarr MG, Hamilton SR, Marrone GC, et al. Barrett's esophagus: Its prevalence and association with adenocarcinoma in patients with symptoms of gastroesophageal reflux. Am J Surg 1985; 149:187-92.

11. Saubier EC, Gouillat C, Samaniego C, et al. Adenocarcinoma in columnarlined Barrett's esophagus. Analysis of 13 esophagectomies. Am J Surg 1985; 150:365-9.

12. Spechler SJ, Goyal RK. Barrett's esophagus. N Engl J Med 1986;315:362-71.

13. Sanfey H, Hamilton SR, Smith RRL, et al. Carcinoma arising in Barrett's esophagus. Surg Gynecol Obstet 1985; 161:570-4.

14. Skinner DB, Welther BC, Riddell RH, et al. Barrett's esophagus: Comparison of benign and malignant cases. Am J Surg 1983;198:554-66

15. Smith RRL, Hamilton SR, Boitnott JR, et al. The spectrum of carcinoma arising in Barrett's esophagus: A clinicopathologic study of 26 patients. Am J Surg Pathol 1984;8:563-73.

16. Berardi RS, Devaiah KA. Barrett's esophagus. Surg Gynecol Obstet 1983; 156:521-38.

17. Skinner DB. The columnar-lined esophagus and adenocarcinoma. Ann Thorac Surg 1985;40:321-2. (Edit)

18. Rosenberg JC, Budev H, Edwards RC, et al. Analysis of adenocarcinoma in Barrett's esophagus utilizing a staging system. Cancer 1985;55:1353-60.

19. Hamilton SR, Smith RRL. The relationship between columnar epithelial dysplasia and invasive adenocarcinoma arising in Barrett's esophagus. Am J Clin Pathol 1987;87:301-12.

20. Lee RG. Dysplasia in Barrett's esophagus. A clinicopathologic study of six patients. Am J Surg Pathol 1985;9:845-52.

21. Belladonna JA, Hajdu SI, Bains MS, et al Adenocarcinoma in situ of Barrett's esophagus diagnosed by endoscopic cytology. N Engl J Med 1974;291:895-6.

22. Winters C, Spurling TJ, Chobanian S], et al. Barrett's esophagus. Gastroenterology 1987;92:118-24.

23. Robbins AH, Vincent ME, Saini M, et al. Revised radiologic concepts of the Barrett's esophagus. Gastrointest Radiol 1978;3:377-81.

24. Levine MS, Kressel HY, Caroline DF, et al. Barrett's esophagus. Reticular pattern of the mucosa. Radiology 1983; 147:663-7.

25. Reid B, Haggitt RC, Rubin CE Rabinovitch PS. Barrett's esophagus: Correlation between flow cytometry and histology in detection of patients at risk for adenocarcinoma. Gastroenterology 1987;93:1-11.

26. Jass JR. Mucin histochemistry of the columnar epithelium of the oesophagus: A retrospective study. J Clin Pathol 1981;34:866-70.

27. Kothari T. Mangla JC, Kalra TMS Barrett's ulcer and treatment with cimetidine. Arch Intern Med $1980 ; 140: 475-7$.

\section{Clinical quiz - Answers}

\section{COLON}

\section{Causes, clinical manifestations and treatment of solitary rectal ulcer}

\author{
Causes \\ Constipation \\ Ergotamine suppositories \\ Idiopathic \\ Manifestations \\ Pain \\ Blood and mucus \\ Treatment \\ Stool softeners \\ Stop ergotamine \\ Local analgesics \\ Rarely, surgery to correct associated rectal prolapse \\ 5-ASA, steroids \\ 2. Clinical features which would make you suspect \\ that a patient was suffering from cathartic colon
}

Recurrent diarrhea with persistent hypokalemia in a female

Melanosis coli in sigmoidoscopy (anthracenes)

Narrow featureless colon on barium enema

Positive sodium hydroxide test - pink stool (phenolphthalein)

\section{NUTRITION}

1. Major clinical manifestations of vitamin A toxicity

Skin lesion - dry, pruritic, coarse and scaly skin Hair loss

Sore mouth, anorexia, vomiting

Headache, drowsiness, irritability, increased intracranial

pressure and papilledema

Enlarged liver progressing to fibrosis and cirrhosis

Lymphadenopathy

Bone pain (painful hyperostosis)

Congenital abnormality in pregnant women

2. Clinical manifestations of zinc deficiency

Diarrhea

Disturbance of central nervous system with mental irritability and depression

Skin lesion of the face, limbs, skin folds and perineum

Alopecia

Loss of taste-ageusia

Defect in the immunologic mechanisn 


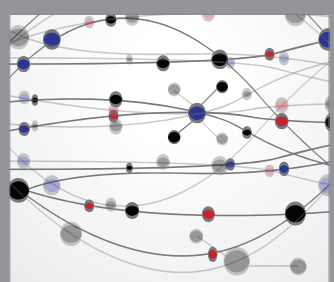

The Scientific World Journal
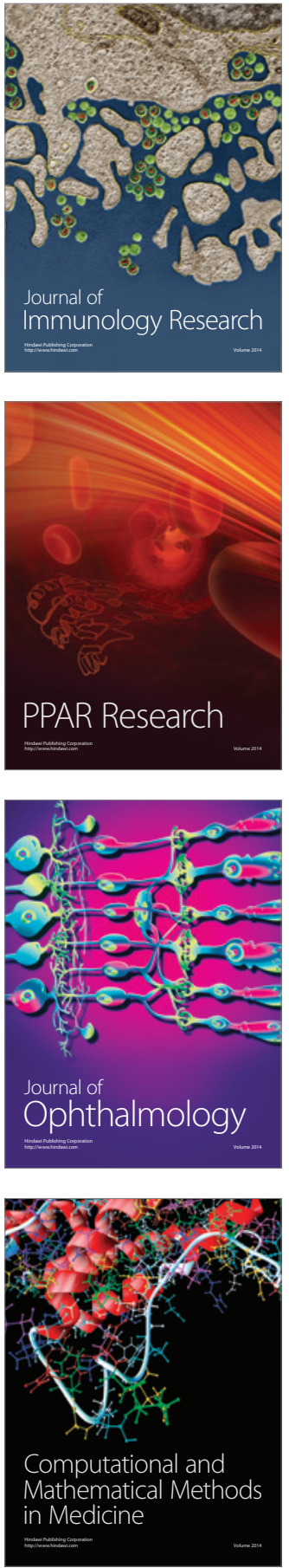

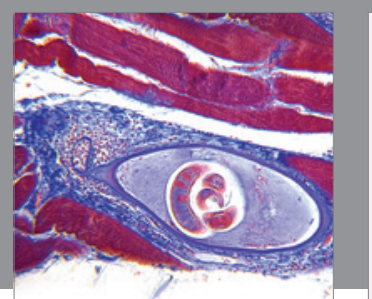

Gastroenterology Research and Practice

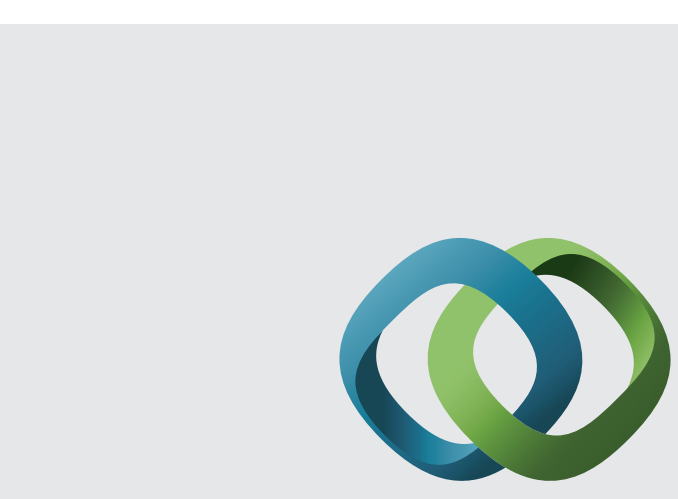

\section{Hindawi}

Submit your manuscripts at

http://www.hindawi.com
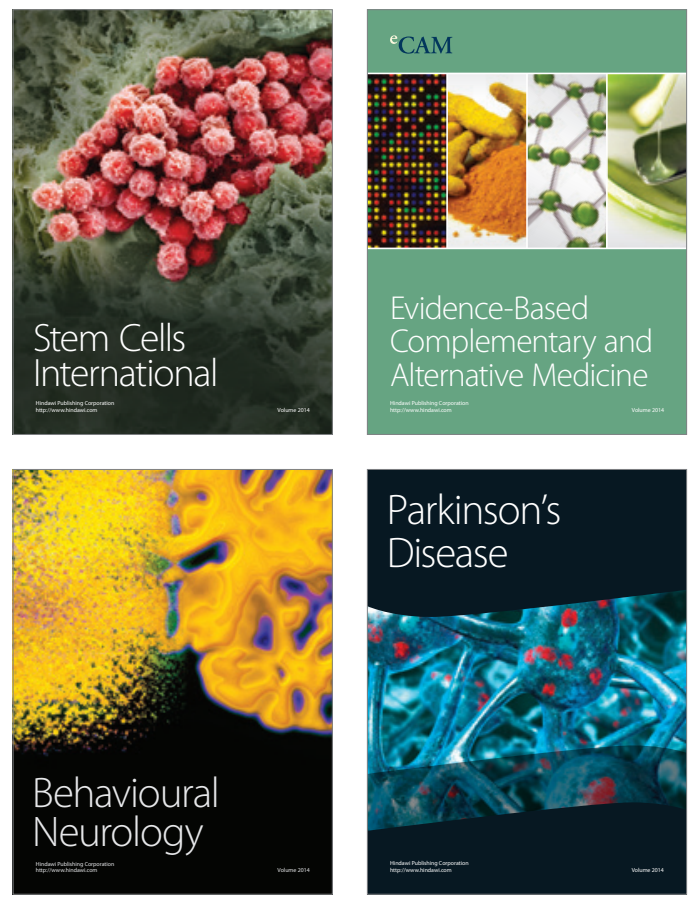
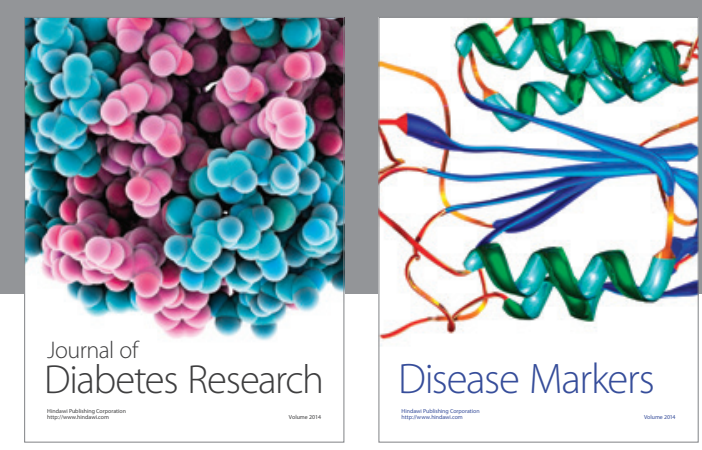

Disease Markers
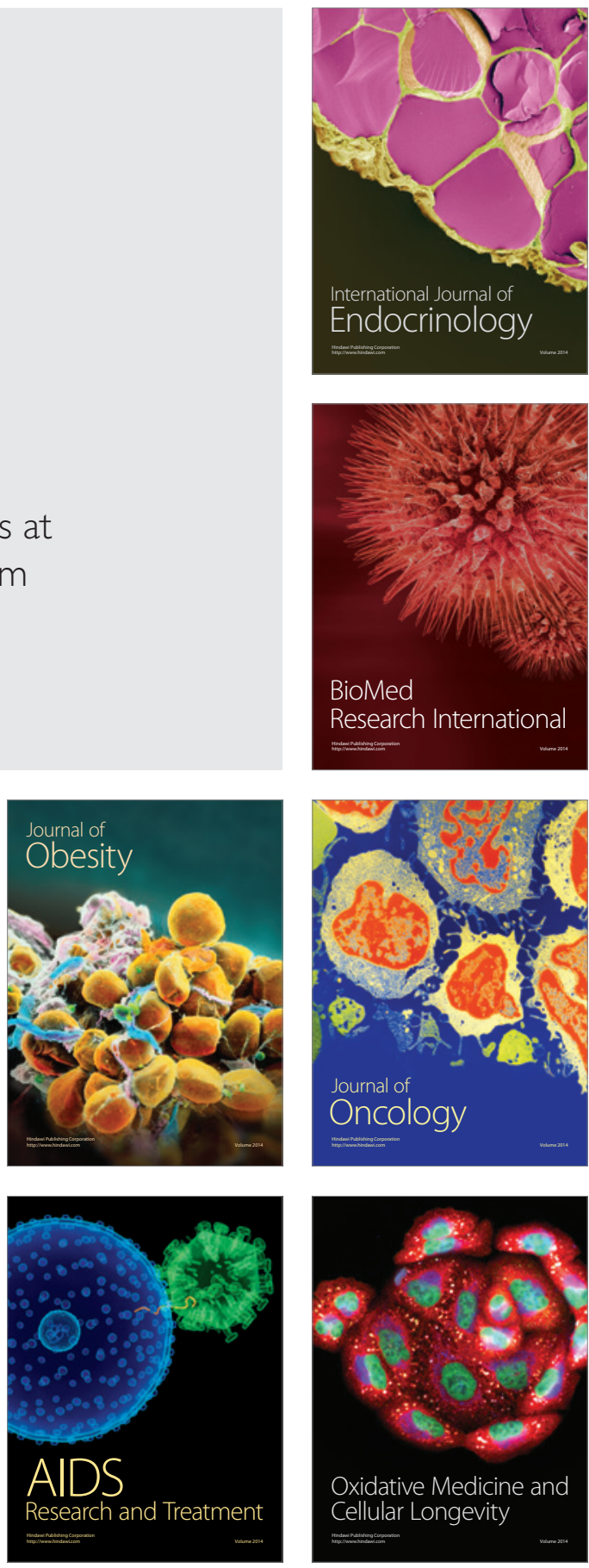